\title{
Sensory conduction study in chronic sensory ataxic neuropathy
}

\author{
Teruhiko Kachi, Gen Sobue, Masahiko Yamamoto, Akihiro Igata
}

\begin{abstract}
Sensory conduction was studied in six patients with chronic sensory ataxic neuropathy of an idiopathic type and associated with Sjögren's syndrome. Motor nerve conduction velocities were normal in most cases, but sensory nerve potentials could not be evoked in a routine peripheral nerve conduction study. Cortical and cervical somatosensory evoked potentials (SEPs) and evoked potentials from Erb's point were barely recorded by median nerve stimulation at the wrist. When the median nerve was stimulated at more proximal points, clear potentials were recorded from Erb's point, but cortical SEPs were still hardly elicited. Thus the sensory nerves are centrally and peripherally involved in this condition, and the involvement is more prominent in the distal portion in the peripheral nerve. These findings suggest that central-peripheral distal axonopathy is a process involved in this illness and that the dorsal root ganglia may be primarily involved, in accord with previous pathological studies.
\end{abstract}

(F Neurol Neurosurg Psychiatry 1994;57:941-944)

Although the underlying causes of chronic neuropathy showing ataxia due to loss of proprioceptive and kinaesthetic sensation with a substantially preserved motor system are malignant tumours, ${ }^{1-3}$ drug intoxication, ${ }^{45}$ or paraproteinaemic neuropathy, ${ }^{6}$ this neuropathy may also be idiopathic ${ }^{7-9}$ or associated with Sjögren's syndrome. ${ }^{9-13}$ Pathological and immunological studies of this condition have suggested that the sensory ganglia may be the primary site of the lesion, ${ }^{8914-16}$ but no physiological study has confirmed this finding. We investigated the sensory nerve conduction in this illness by routine nerve conduction studies and measurement of somatosensory evoked potentials (SEPs).

\section{Patients and methods}

Six patients were examined in this study, and the table summarises their sex, age, and age at onset. The patients' height ranged from 155 to $165 \mathrm{~cm}$, and was not different from that in the normal control subjects. Although three patients (patients 4, 5, and 6) had Sjögren's syndrome and three were of an idiopathic type, we included them, because these two conditions show the same clinical and pathological features. ${ }^{9}$ The diagnosis of Sjögren's syndrome was essentially established by criteria described by Fox $e t a l^{17}$ and by criteria proposed by the Diagnostic Committee for the Sjögren's Syndrome Study Group of the Ministry of Health and Welfare of Japan. ${ }^{18}$ None of the patients had a family history of neurological disease, or other diseases such as diabetic, amyloid, vasculitic, tabetic, nutritional, or toxic neuropathies. Malignancy was not found in any of the patients during the course of the neuropathy (4-14 years) despite a systemic search. The illness started in middle age with sensory disturbance in the thumb, finger or toe, which very slowly spread to all the extremities. Patients 4, 5, and 6 had siccative symptoms such as hypolacrimation and hyposalivation as well as neurological symptoms. Deep reflexes were absent in both the upper and the lower extremities in all the patients. Muscle strength was normal in all except one patient, who showed slight weakness in the distal portion of the upper extremities. All modalities of sensation were involved, among them deep vibratory and kinaesthetic sensations were particularly disturbed, causing sensory ataxia. The sensory disturbance was distributed in all the extremities in a distally accentuated manner and in the trunk as well, the distribution of which was not like the complete glove and stocking type seen in polyneuropathies, but showed a multifocal pattern similar to that in multiple mononeuropathy..$^{91213}$ Adie's pupils and/or orthostatic hypotension were seen in four patients. The serum IgG concentration was raised in three patients, but no patient showed abnormal immunoglobulin concentrations in CSF. Needle electromyographic examination (EMG) showed only mild denervation in the hand muscles in patient 1, and EMG showed no abnormality in the other patients. Sural nerve biopsy performed in five patients showed decreased density of myelinated fibres, especially the large sized ones.

Routine nerve conduction velocities were measured in the median, tibial, and sural nerves in all the patients. Because each had sensory disturbance and ataxia in the upper as well as in the lower extremities without obvious laterality, the right median nerve was chosen for somatosensory evoked potentials (SEPs). As described before, ${ }^{19}$ the patients were asked to sit comfortably in a chair with their arms relaxed and supported on the arms of the chair. The right median nerve was stimulated at the wrist and elbow separately in all 


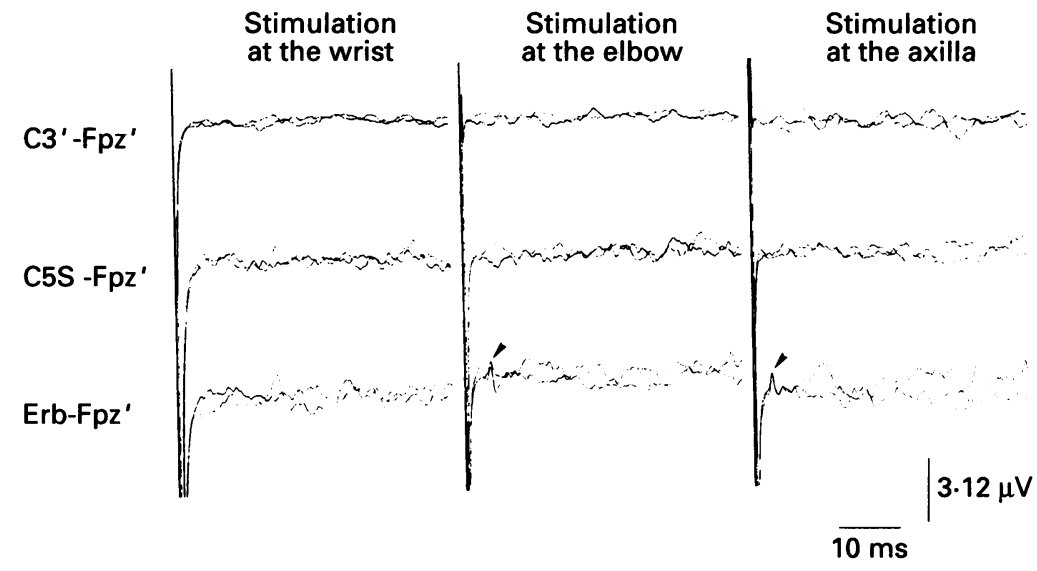

SEPs by right median nerve stimulation in patient 2. No cortical or cervical SEPs were recorded at any site of the nerve being stimulated. When the nerve was stimulated at the elbow and axilla, only Erb's N9 could be recorded. C3' and Fpz' $=2 \mathrm{~cm}$ posterior to C3 and Fpz of the international 10-20 system; C5S = spinous process. Arrows indicate N9.

the patients. In four patients, the nerve was also stimulated at the axilla where the action potentials were evoked only in the muscles innervated by the median nerve. The SEPs were recorded from the contralateral parietal scalp $(2 \mathrm{~cm}$ posterior to $\mathrm{C} 3$ of the international 10-20 system), the posterior neck at the level of the $\mathrm{C} 5$ spinous process, and the right Erb's point with $\mathrm{Ag} / \mathrm{AgCl}$ surface electrodes, diameter about $10 \mathrm{~mm}$. A common reference electrode was placed on the forehead $(2 \mathrm{~cm}$ posterior to $\mathrm{Fpz}$ ). Electrical stimulation was applied at $3 \mathrm{~Hz}$ with pulses of $0.1 \mathrm{~ms}$ in duration, and an intensity of about $20 \%$ above the motor threshold. A total of 500 sweeps was averaged and stored with an electromyograph (Nihon Kohden MEM 4104). The filter was set at $20 \mathrm{~Hz}$ (low cut) and $3 \mathrm{kHz}$ (high cut). N20 in the cortical SEPs, N13 in the cervical SEPs, and the negative peak at Erb's point (N9) were selected for evaluation. Amplitude

Physiological findings for the six patients

\begin{tabular}{|c|c|c|c|c|c|c|c|}
\hline $\begin{array}{l}\text { Patient } \\
\text { Sex } \\
\text { Age (y) } \\
\text { Age at onset (y) }\end{array}$ & $\begin{array}{l}1 \\
M \\
64 \\
56\end{array}$ & $\begin{array}{r}2 \\
M \\
58 \\
51\end{array}$ & $\begin{array}{l}F^{3} \\
53 \\
49\end{array}$ & $\begin{array}{l}4 \\
F \\
55 \\
47\end{array}$ & $\begin{array}{l}5 \\
F \\
69 \\
61\end{array}$ & $\begin{array}{l}{ }^{6} \\
F \\
76 \\
62\end{array}$ & Normal limits \\
\hline \multicolumn{8}{|c|}{ Routine nerve conduction study: } \\
\hline $\begin{array}{l}\text { Median SCV } \\
\text { amplitude }(\mu \mathrm{V})\end{array}$ & NE & NE & $\begin{array}{r}50 \cdot 2 \\
3 \cdot 2\end{array}$ & NE & $\underline{\mathrm{NE}}$ & NE & \\
\hline \multicolumn{8}{|c|}{ Latency of somatosensory evoked potentials (ms) and amplitude of $N 9$} \\
\hline \multicolumn{8}{|c|}{ Stimulation at the wrist: } \\
\hline Cortical N20 & 23.6 & NE & $19 \cdot 0$ & NE & NE & $22 \cdot 2$ & $21 \cdot 1>$ \\
\hline Cervical N13 & $\mathrm{NE}$ & $\mathrm{NE}$ & $13 \cdot 2$ & $\mathrm{NE}$ & $\mathrm{NE}$ & $\mathrm{NE}$ & $15 \cdot 5>$ \\
\hline Erb's point N9 & $\mathrm{NE}$ & $\mathrm{NE}$ & $9 \cdot 1$ & $8 \cdot 8$ & $\mathrm{NE}$ & $\mathrm{NE}$ & $10 \cdot 9>$ \\
\hline N9 amplitude $(\mu \mathrm{V})$ & - & - & $3 \cdot 1$ & 0.9 & - & - & \\
\hline $\operatorname{CSCT}(\mathrm{ms})$ & - & - & $5 \cdot 8$ & - & - & - & 6.9> \\
\hline \multicolumn{8}{|l|}{ Stimulation at the elbow: } \\
\hline Cortical N20 & $15 \cdot 5$ & NE & $15 \cdot 7$ & NE & NE & $18 \cdot 1$ & $17 \cdot 8>$ \\
\hline Cervical N13 & $\mathrm{NE}$ & NE & $9 \cdot 2$ & $\mathrm{NE}$ & $\mathrm{NE}$ & $\mathrm{NE}$ & $11 \cdot 8>$ \\
\hline Erb's point N9 & $5 \cdot 4$ & $5 \cdot 6$ & $5 \cdot 0$ & $5 \cdot 7$ & $5 \cdot 0$ & $5 \cdot 4$ & $7 \cdot 1>$ \\
\hline N9 amplitude $(\mu \mathrm{V})$ & 0.9 & 0.6 & $3 \cdot 8$ & $3 \cdot 4$ & $16 \cdot 4$ & $2 \cdot 1$ & \\
\hline $\mathrm{CSCT}(\mathrm{ms})$ & - & - & 6.5 & - & - & - & $6 \cdot 8>$ \\
\hline \multicolumn{8}{|l|}{ Stimulation at the axilla: } \\
\hline Cortical N20 & ND & NE & 13.9 & ND & $\mathrm{NE}$ & $14 \cdot 4$ & $15 \cdot 6>$ \\
\hline Cervical N13 & ND & $\mathrm{NE}$ & $7 \cdot 4$ & ND & $\mathrm{NE}$ & $7 \cdot 3$ & 9.9> \\
\hline Erb's point N9 & ND & 3.9 & $3 \cdot 0$ & ND & 2.9 & $3 \cdot 2$ & $5 \cdot 3>$ \\
\hline N9 amplitude $(\mu \mathrm{V})$ & - & $1 \cdot 3$ & $6 \cdot 9$ & - & $17 \cdot 5$ & $13 \cdot 8$ & \\
\hline CSCT & - & - & 6.5 & - & - & $7 \cdot 1$ & $6 \cdot 8>$ \\
\hline \multicolumn{8}{|c|}{ Estimated SCV by cortical $\mathrm{N} 20(\mathrm{~m} / \mathrm{s})$ : } \\
\hline Wrist elbow & $29 \cdot 2$ & - & 63.6 & - & - & $37 \cdot 1$ & $48.9<$ \\
\hline Elbow axilla & - & - & $66 \cdot 7$ & - & - & 43.9 & $55 \cdot 9<$ \\
\hline
\end{tabular}

SCV = sensory nerve conduction velocity; $\mathrm{CSCT}=$ central sensory conduction time; $\mathrm{NE}=$ no evoked; ND $=$ not done; $-=$ not measurable; Normal limits for SEPs were estimated from 10 normal control subjects as mean $-3 S D$ for conduction velocity and mean $+3 S D$ for conduction time. of the negative peak from the preceding small positive peak at Erb's point was measured as amplitude of N9. The difference in latency between cortical $\mathrm{N} 20$ and cervical N13 was estimated as being the central sensory conduction time (CSCT). The difference in latency of $\mathrm{N} 20$ between stimuli at the wrist, the elbow, and the axilla was estimated as being the sensory conduction velocity (SCV) from the wrist to the elbow and from the elbow to the axilla. Informed consent was obtained from all the patients.

\section{Results}

ROUTINE NERVE CONDUCTION VELOCITIES

Routine peripheral motor nerve conduction velocities (MCVs) were normal in the median and tibial nerves in all the patients except one (patient 1), whose tibial MCV showed a slight reduction $(37.5 \mathrm{~m} / \mathrm{s})$. The amplitude of the evoked action potentials was within normal limits in both nerves in all the patients. In patient 3 the SCV in the median nerve was $50.2 \mathrm{~m} / \mathrm{s}$ with low amplitude of $3.2 \mu \mathrm{V}$. In patient 6 , the SCV in the sural nerve was 40.4 $\mathrm{m} / \mathrm{s}$ with a decreased amplitude of $1 \cdot 2 \mu \mathrm{V}$. No sensory nerve potentials were evoked in the other four patients.

\section{SOMATOSENSORY EVOKED POTENTIALS}

In normal controls SEPs were clearly recorded wherever the median nerve was stimulated. Amplitude of $\mathrm{N} 20$ and N13 was not changed with the stimulated site. Amplitude of Erb's N9 differed from subject to subject. When the median nerve was stimulated at the wrist in the normal control subjects, the amplitude of N9 was 5.5 to $12.8 \mu \mathrm{V}$ with a mean of $8.0(\mathrm{SD} 2.48) \mu \mathrm{V}$. The N9 potential was much larger with stimulation of the median nerve at the elbow than at the wrist in each subject. Relative size of the N9 potential with stimulation at the elbow compared with that with stimulation at the wrist was $200 \%$ to $240 \%$. By contrast, the amplitude of N9 with stimulation at the axilla was similar to that with stimulation at the elbow. Relative size of N9 potential with stimulation at the axilla when compared with that with stimulation at the elbow was $109 \%$ to $115 \%$.

The figure shows typical recordings for one patient. The table summarises results of SEPs in all six patients. When the median nerve was stimulated at the wrist, no cortical N20, cervical N13, or Erb's N9 was obtained in two patients (patients 2 and 5). Only cortical N20 could be recorded in two patients (patients 1 and 6), and the latency of the N20 was prolonged. Cortical N20, cervical N13, and Erb's N9 were recorded with normal latency in one patient (patient 3). N9 was recorded from Erb's point in patient 4 . When the median nerve was stimulated at the elbow, Erb's N9 could be evoked in all the patients, and the latency was normal. Neither cortical N20 nor cervical N13 was elicited in three patients (patients 2, 4, and 5), and latency of N20 was prolonged in one patient (patient 6). The median nerve was stimulated at the axilla in 
four patients. Cortical N20 and cervical N13 were recorded in two patients (patients 3 and 6 ), and their latencies were normal, whereas these could not be recorded in patients 2 and 5. Central sensory conduction time was prolonged in one patient (patient 6) when the median nerve was stimulated at the elbow. In patient 4 the amplitude of N9 with stimulation at the elbow was about four times that with stimulation at the wrist. Patients 2, 3, and 4 showed much larger amplitude of N9 with axilla stimulation in comparison with elbow stimulation. The estimated SCV by the cortical N20 was reduced in two of three patients whose cortical SEPs were recorded.

\section{Discussion}

Our six patients were diagnosed as having a relatively rare form of chronic neuropathy in which sensory disturbance causing ataxia is dominant. ${ }^{89}$ The results of the conduction studies were indistinguishable between idiopathic cases and Sjögren's syndrome associated cases (table). Clinical characteristics of the neurological symptoms were also similar between these two groups as described, suggesting that the underlying pathophysiology is common to the chronic ataxic neuropathies in this study. Peripheral nerve conduction studies have shown severe sensory nerve involvement with substantial preservation of motor nerves..$^{715}$ In our present study, needle EMG and motor nerve conduction velocities showed normal values in most cases, indicating that the peripheral motor nerves were well preserved in this illness. By contrast, sensory nerve potentials were barely evoked, and no SEPs were recorded from Erb's point or from the cortex in three cases when the median nerve was stimulated at the wrist. When the median nerve was stimulated at more proximal portions, SEPs could be recorded from the Erb's point. Furthermore, there is a pronounced amplitude gradient in N9 between elbow and axilla stimulation. As the median nerve was stimulated above the origin of the pronator teres and the same fibre population is stimulated at both elbow and axilla levels of the median nerve, there should be no major gradient. In fact, the amplitude of N9 with axilla stimulation is not much different from that with elbow stimulation in the normal controls. N20 of the cortical SEPs was still hardly recorded with proximal stimulation of the median nerve. The evoked potentials obtained from Erb's point might be antidromic motor nerve potentials. ${ }^{1120}$ As the compound action potentials were clearly recorded in the thenar muscles when the median nerve was stimulated at the wrist, elbow, and axilla, and the needle EMG showed few abnormal findings in the examined muscles including the thenar muscle, the nerve potentials of motor nerve origin should be evoked at Erb's point when the median nerve was stimulated at the wrist. It is known that SEPs are amplified in the CNS and if the central rami of the primary sensory neurons are intact, the SEPs can be recorded from the cerebral cortex, even though the peripheral sensory nerve potentials cannot be evoked by routine peripheral nerve conduction studies due to the loss of axons in the peripheral rami. ${ }^{20}$ Under these conditions, SCV could be measured by SEPs. ${ }^{20}$ In fact, in polyneuropathy associated with pigmentation, hypertrichosis, oedema, and plasma cell dyscrasia (Crow-Fukase syndrome) in which the peripheral nervous system is involved in a distally accentuated manner ${ }^{21}$ and the routine SCV can be hardly recorded ${ }^{21}$ while the CNS is well preserved, ${ }^{21}{ }^{22}$ the cortical component of SEPs is normally recorded. ${ }^{22}$ In our patients the cortical SEPs were hardly recorded even when the median nerve was stimulated at the most proximal portion. Similar findings were reported in patients with Friedreich's ataxia, ${ }^{202324}$ in which the central rami of the primary sensory neurons are degenerated. Thus the electrophysiological findings in our present study indicate that the peripheral branches of the axons of the primary sensory neurons were lost in a distally accentuated manner and that the central branches were also profoundly involved. Therefore, centralperipheral distal axonopathy ${ }^{25}$ may be the process involved in this neuropathy. On the other hand, Chang et $a l^{26}$ reported a case of podophyllin induced acute ataxic neuronopathy in which stimulation of the ulnar nerve evoked no potentials at Erb's point, neck, or scalp, suggesting that the lesion is localised in the dorsal root ganglia. It would be difficult to separate ganglionopathy from central-peripheral distal axonopathy by physiological means. We do not think that central-peripheral distal axonopathy is always due to damage of the dorsal root ganglia. It has recently been suggested, however, that the dorsal root ganglia are pathologically and primarily involved with $T$ cell invasion in cases associated with Sjögren's syndrome. ${ }^{9111227}$ The results of our present study are consistent with this pathological view of ganglioneuronopathy. This work was supported by a grant from the Research Japan.

1 Denny-Brown D. Primary sensory neuropathy with muscular changes associated with carcinoma. 7 Neurol Neurosurg Psychiatry 1948;11:73-87.

2 Croft PB, Henson RA, Urich H, Wilkinson PC. Sensory neuropathy with bronchial carcinoma; a study of 4 cases showing serological abnormalities. Brain 1965;88: 501-14

3 Ohnishi A, Ogawa M. Preferential loss of large lumbar sensory neurons in carcinomatous sensory neuropathy. Ann Neurol 1986;20:102-4.

4 Hadley D, Herr HW. Peripheral neuropathy associated with cisdichlor diamminoplatinum (II) treatment. Cancer 1979;44:2026-32.

5 Schaumberg G, Kaplan J, Windebank A, et al. Sensory neuropathy from pyridoxine abuse: a new megavitamin syndrome. $N$ Engl $\Im \mathrm{Med}$ 1983;309:445-8.

6 Smith IS, Kahn SN, Lacey BW, King RHM, Eames RA Whybrew DJ, Thomas PK. Chronic demyelinating neuWhybrew DJ, Thomas PK. Chronic demyelinating neuropathy associated with

7 Kaufman MD, Hopkins LC, Hurwitz BJ. Progressive sensory neuropathy without carcinoma: a disorder with dissory neuropathy without carcinoma: a disorder with distinctive clinical and el

8 Dalakas MC. Chronic idiopathic ataxic neuropathy. Ann Neurol 1986;19:545-54.

9 Sobue G, Yasuda T, Kachi T, Sakakibara T, Mitsuma T. 
Chronic progressive sensory ataxic neuropathy: clinicopathological features of idiopathic and Sjögren's syndrome-associated cases. $\mathcal{F}$ Neurol 1993;240:1-7.

10 Kennett RP, Harding AE. Peripheral neuropathy associated with the sicca syndrome. $f$ Neurol Neurosurg Psychiatry 1986;49:90-2.

11 Malinow $\mathrm{K}$, Yannakakis GD, Glusman $\mathrm{MD}$, et al. Subacute sensory neuronopathy secondary to dorsal root ganglionitis in primary Sjögren's syndrome. Ann Neurol 1986;20:535-7.

12 Griffin JW, Cornblath D, Alexander E, et al. Ataxic sensory neuropathy and dorsal root ganglionitis associated sory neuropathy and dorsal root ganglionitis associated
with Sjögren's syndrome. Ann Neurol 1990;27:304-15.

13 Kumazawa K, Sobue G, Yamamoto K, Mitsuma T. Segmental anhidrosis in the spinal dermatomes in Sjögren's syndrome-associated neuropathy. Neurology 1993;43:1820-3.

14 Sobue G, Yanagi T, Hashizume Y. Chronic progressive sensory ataxic neuropathy with polyclonal gammopathy and disseminated focal perivascular cellular infiltration. Neurology 1983;38:463-7.

15 Mamoli A, Nemni R, Camelingo M, et al. A clinical, electrophysiological, morphological and immunologica study of chronic sensory neuropathy with ataxia and paraesthesia. Acta Neurol Scand 1992;85:110-5.

16 Simon LT, Ricaurte GA, Forno SL. Chronic idiopathic ataxic neuropathy: neuropathology of a case. Acta ataxic neuropathy: neuropathology
Neuropathol (Berl) 1989;79:104-7.

17 Fox RI, Robinson CA, Curd JG, et al. Sjögren's syndrome, proposed criteria for classification. Arthritis Rheum 1986;29:577-85.

18 Research Committee of Sjögren's Syndrome. Diagnostic criteria for Sjögren's syndrome. Tokyo: Annual report on research for intractable diseases, the Ministry of Health and Welfare of Japan, 1977.

19 Kachi T, Sobue G, Sobue I. Central motor and sensory conduction in $\mathrm{X}$-linked recessive bulbospinal neuronopathy. F Neurol Neurosurg Psychiatry 1992;55:394-7.

20 Desmedt JE. Cerebral evoked potentials. In: Dyck PJ, et al, eds. Peripheral neuropathy. Philadelphia: WB Saunders Co, 1984:1045-66.

21 Sobue G, Doyu M, Watanabe M, Hayashi F, Mitsuma T. Extensive demyelinating changes in the peripheral nerves of Crow-Fukase syndrome: a pathological study
of one autopsied case. Acta Neuropathol (Berl) 1992;84: of one

22 Shibasaki H, Ohnishi A, Kuroiwa Y. Use of SEPs to localize degeneration in a rare polyneuropathy: studies on polyneuropathy associated with pigmentation, hypertrichosis, edema, and plasma cell dyscrasia. Ann Neurol $1982 ; 12: 355-60$

23 Jones SJ, Baraitser M, Halliday AM. Peripheral and central somatosensory nerve conduction in Friedreich's ataxia. $\mathcal{F}$ Neurol Neurosurg Psychiatry 1980;43:495-503.

24 Caruso G, Santoro L, Perretti A, et al. Friedreich's ataxia: electrophysiologic and histologic findings in patients and relatives. Muscle Nerve 1987;10:503-15.

25 Spencer PS, Schaumberg HH. Ultrastructural studies of the dying-back process. III. The evolution of experimental peripheral giant axonal degeneration. ¥Neuropathol Exp Neurol 1977;36:276-99.

26 Chang M-H, Lin K-P, Wu Z-A, Liao K-K Acute ataxic sensory neuronopathy resulting from podophyllin intoxisensory neuronopathy resulting from

27 Adamson T, Fox R, Frisman D, Howell F. Immunohistologic analysis of lymphoid infiltrates in primary Sjögren's syndrome using monoclonal antibodies. $f$ Immunol 1983;130:203-8. 